\title{
AVALIAÇÃO DO BEM-ESTAR EM FUNÇÃO DAS CARACTERISTICAS DE AMBIENTES DISTINTOS
}

\section{EVALUACIÓN DEL BIENESTAR SEGÚN LAS CARACTERÍSTICAS DE LOS DIFERENTES ENTORNOS}

\author{
ASSESSMENT OF WELL-BEING ACCORDING TO THE CHARACTERISTICS OF DIFFERENT \\ ENVIRONMENTS
}

\section{PENTEADO, ANA CAROLINA BONINI}

Mestre em Engenharia Civil, Universidade Tecnológica Federal do Paraná, anapenteado@alunos.utfpr.edu.br

\section{IAROZINSKI NETO, ALFREDO}

Doutor em ciências, Universidade Tecnológica Federal do Paraná, iarozinski@professores.utfpr.edu.br

\section{RESUMO}

A influência que o ambiente construído exerce sobre o bem-estar dos seres humanos é notória, visto que, se forem mal projetados, os mesmos geram um impacto negativo na qualidade de vida de seus usuários. Dessa maneira, o entendimento acerca de como as pessoas percebem os ambientes é importante, tornando-se necessário o desenvolvimento de instrumentos capazes de avaliar a percepção e o bem-estar dentro do ambiente construído. Neste âmbito, o presente trabalho tem por objetivo aplicar a escala PANAS (Escala de Afeto Positivo e Negativo) de Watson e Tellegen (1985) para avaliar o impacto das variações das características do ambiente construído interno nos sentimentos dos indivíduos. Para tanto, realizou-se um experimento composto pela aplicação de um questionário composto por 48 sentimentos derivados da mesma escala a fim de determinar quais sentimentos são mais sensíveis à variação das características de cinco ambientes distintos. 0 questionário foi aplicado a 143 estudantes dos cursos de Engenharia Civil e Arquitetura e Urbanismo de uma Universidade. A partir do experimento, os resultados confirmaram que ambientes que possuem diferentes características projetuais tendem a despertar diferentes percepções em seus usuários, que associam à cada ambiente particular, sentimentos relacionados ao bem-estar ou mal-estar, adequando-se ao modelo preconizado pela escala PANAS.

PALAVRAS-CHAVE: escala; percepção; ambiente construído; ferramenta de avaliação.

\section{RESUMEN}

Es notoria la influencia que tiene el entorno construido en el bienestar de los seres humanos, ya que si está mal diseñado, tiene un impacto negativo en la calidad de vida de sus usuarios. Por tanto, es importante comprender cómo las personas perciben los entornos, por lo que es necesario desarrollar instrumentos capaces de evaluar la percepción y el bienestar dentro del entorno construido. En este contexto, el presente trabajo tiene como objetivo aplicar la escala PANAS (Scale of Positive and Negative Affection) de Watson y Tellegen (1985) para evaluar el impacto de las variaciones en las características del entorno construido interno sobre los sentimientos de los individuos. Para ello, se realizó un experimento mediante la aplicación de un cuestionario compuesto por 48 sentimientos derivados de la misma escala con el fin de determinar qué sentimientos son más sensibles a la variación en las características de cinco ambientes diferentes. El cuestionario se aplicó a 143 estudiantes de los cursos de Ingeniería Civil y Arquitectura y Urbanismo de una Universidad. A partir del experimento, los resultados confirmaron que entornos que tienen diferentes características de diseño tienden a despertar diferentes percepciones en sus usuarios, que asocian a cada entorno particular, sentimientos relacionados con el bienestar o malestar, adaptándose al modelo recomendado por la escala PANAS.

PALABRAS CLAVES: escala; percepción; entorno construido; herramienta de evaluación.

\section{ABSTRACT}

The influence that the built environment has on the well-being of human beings is notorious, since if poorly designed, they have a negative impact on the quality of life of its users. Thus, understanding about how people perceive environments is important, making it necessary to develop instruments capable of assessing perception and well-being within the built environment. In this context, the present work aims to apply the PANAS scale (Scale of Positive and Negative Affection) by Watson and Tellegen (1985) to assess the impact of variations in the characteristics of the internal built environment on the feelings of individuals. To this end, an experiment was carried out by applying a questionnaire composed of 48 feelings derived from the same scale in order to determine which feelings are most sensitive to the variation in the characteristics of five different environments. The questionnaire was applied to 143 students of the Civil Engineering and Architecture and Urbanism courses at a University. From the experiment, the results confirmed that environments that have different design characteristics tend to arouse different perceptions in their users, which associate to each particular environment, feelings related to well-being or malaise, adapting to the model recommended by the scale PANAS.

KEYWORDS: scale; perception; built environment; assessment tool. 


\section{INTRODUÇÃO}

O ambiente construído é uma entidade complexa, resultado da associação entre espaços, fluxos, experiências, objetos e eventos. Cada ambiente dispõe de qualidades específicas e, mesmo que características compartilhadas existam, elas variam de um lugar para outro (SAYEGH et al., 2016). Segundo Reis e Lay (2006), o ambiente construído é um meio de comunicação não verbal, apto a promover pistas para o comportamento humano. A ligação entre o ambiente construído e o comportamento humano está relacionada às estruturas sociais e culturais de uma época e, as condições geradas no ambiente são aptas a alterar o modo de vida das pessoas e também podem se aperfeiçoar diante das necessidades dos usuários, criando, assim, uma combinação recíproca entre ambiente e ser humano (ORNSTEIN, 1995; SOBRAL et al., 2015).

Pode-se dizer que há um sucessivo interesse em avaliações ambientais e pode-se encontrar um número relevante de ferramentas para essa categoria de avaliação, com foco no uso de energia em edifícios, materiais de construção, clima interno, entre outros aspectos, dentre eles o viés psicológico (FOBERG; MALMBORG, 2004). Para Sobral et al. (2015) mostra-se necessário compreender de que maneira o meio ambiente interage com os usuários, assim como a forma em que os sentimentos são revelados e como estes são traduzidos na percepção ambiental de acordo com certos estímulos, visto que tais elementos têm uma relação direta com reações e comportamento humano.

Verificada a influência das emoções tanto no bem-estar das pessoas quanto nas próprias decisões de compra, evidencia-se que tanto o conhecimento de como os ambientes construídos despertam sentimentos, quanto a avaliação do impacto emocional, possam ser úteis para a prática da construção civil. Dessa forma, o presente trabalho tem por objetivo avaliar comparativamente a variação dos sentimentos de bem-estar em indivíduos em função da variação das características e usos ambientes distintos.

\section{DESENVOLVIMENTO}

As primeiras etapas dessa pesquisa exploratória consistiram na contextualização do problema e na revisão bibliográfica sobre o tema, após as quais foi elaborado um experimento cujo desenvolvimento seguiu as etapas indicadas na Figura 1.

Figura 1: Etapas para elaboração e aplicação do experimento.

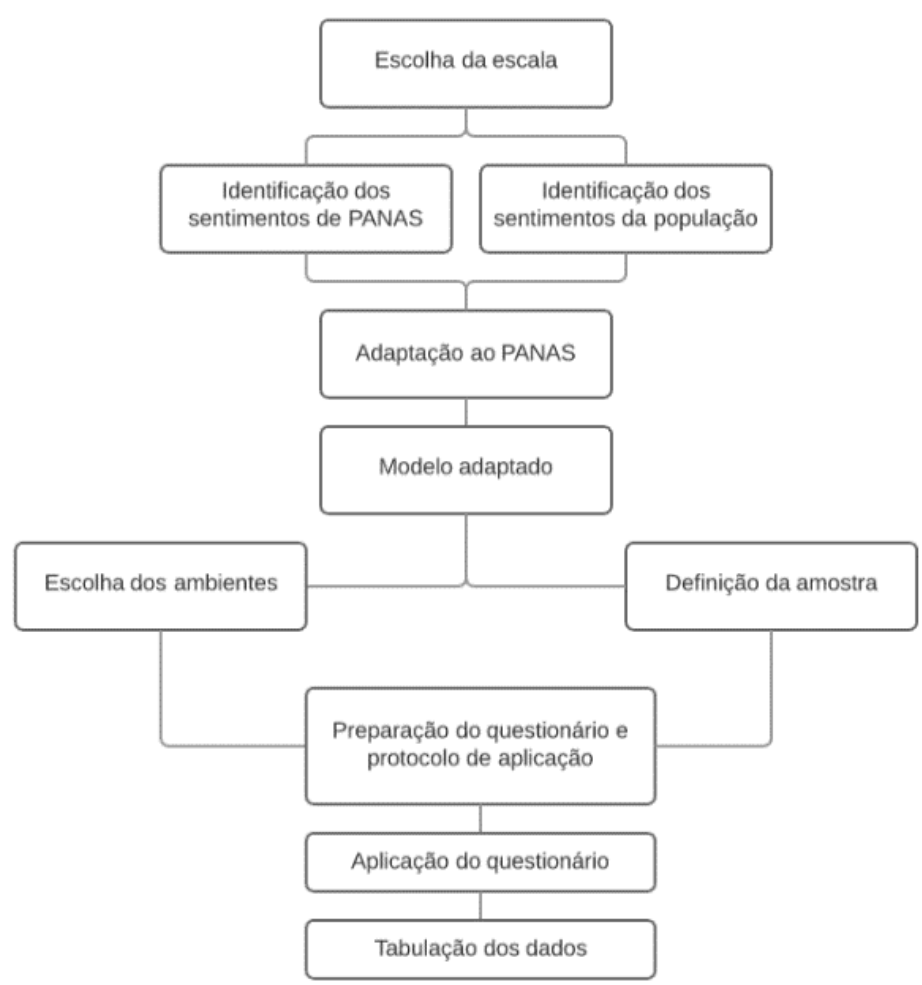

Fonte: Autores (2020). 
A fim de dispor de uma escala para avaliar o sentimento de bem-estar, fez-se necessária a escolha de um instrumento adequado aos objetivos da pesquisa. A escala a ser escolhida deveria atender a três critérios: ser abrangente, genérica e já ter sido aplicada em estudos referentes ao ambiente construído. A partir dos estudos na literatura, verificou-se que a escala PANAS (Positive and Negative Affect Schedule) seria a mais adequada, pois representa a estrutura bidimensional do afeto e já foi utilizada em pesquisas relacionadas ao ambiente construído (GALÁN-DÍAZ, 2011; KNEZ; KERS, 2000; ALBUQUERQUE; TRÓCCOLI, 2004). Além disso, ela permanece como uma das escalas de afeto mais utilizadas e mais validadas em vários países, considerada a que melhor mensura o afeto e descreve suas estruturas (BUZ et al. 2015; GALINHA; RIBEIRO, 2005), sendo consistentemente confirmado que fornece uma boa cobertura do léxico afetivo dos entrevistados (CRAWFORD; HENRY, 2004).

Desenvolvida por Watson, Clark e Tellegen (1988) (Figura 2), a escala PANAS é um modelo circular, bidimensional, em que a variável do afeto descreve duas dimensões vastas de emoções básicas que se manifestam consistentemente nos estudos realizados -0 afeto positivo e o afeto negativo.

O primeiro fator, chamado de afeto positivo, equivale à pessoa anunciar ter entusiasmo pela vida. O segundo fator, afeto negativo, é verificado quando a pessoa relata se sentir chateada ou perturbada. Tais fatores são apresentados como dimensões descritivamente bipolares, mas afetivamente unipolares (WATSON; TELLEGEN, 1985). O afeto positivo elevado é um estado de alta energia e engajamento prazeroso, enquanto o afetivo positivo baixo é caracterizado pela letargia; em contraste, o afeto negativo alto é uma dimensão geral de angústia e engajamento desagradável, incluindo desprezo, desgosto, culpa e nervosismo, e o afeto negativo baixo é um estado de calma e serenidade (WATSON; CLARK; TELLEGEN, 1988).

Figura 2: Escala Panas.

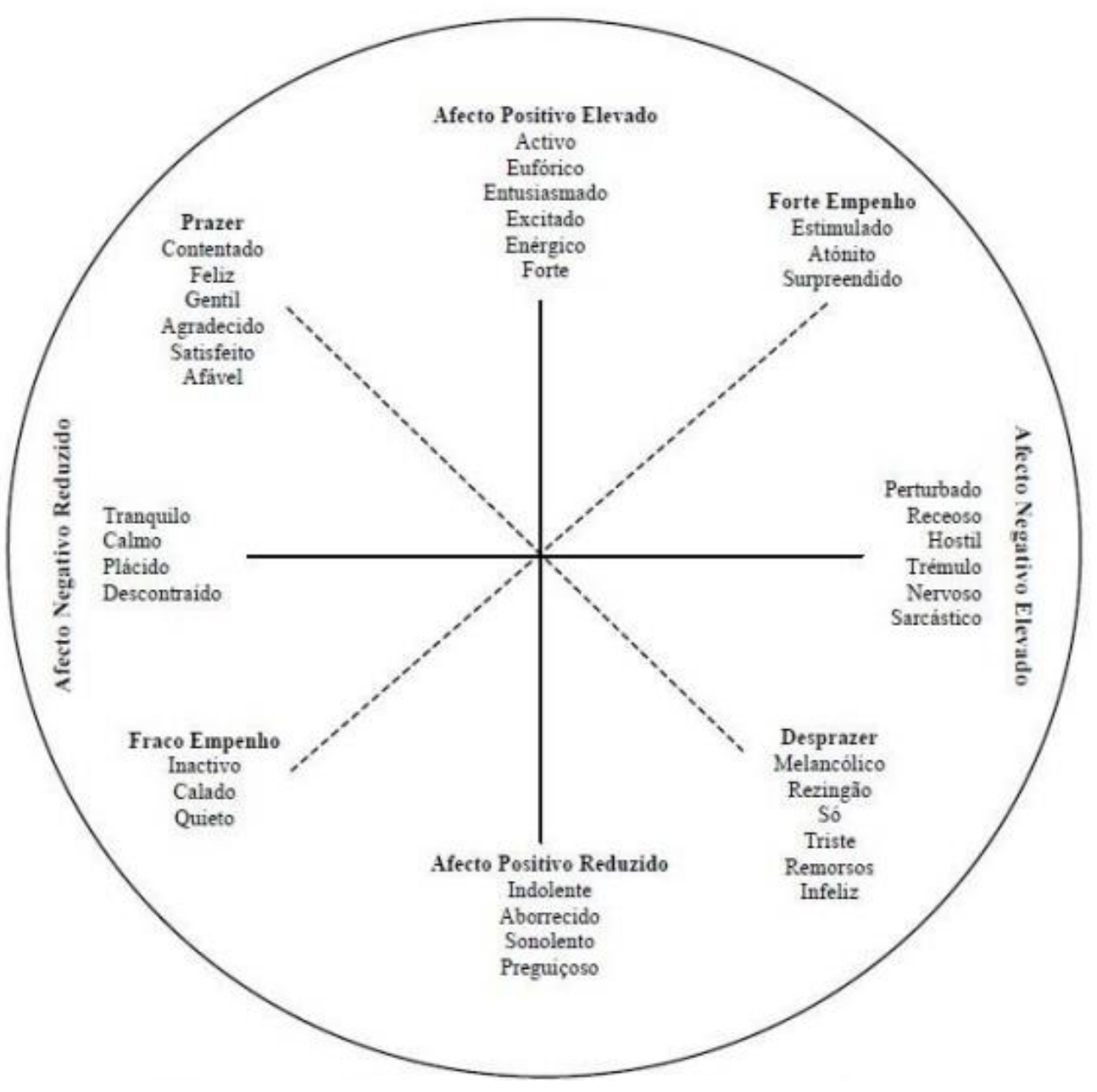

Fonte: Galinha e Ribeiro (2005). 
Segundo Watson e Tellegen (1985) o eixo referente ao prazer contém termos que representam uma mistura de alto efeito positivo e baixo efeito negativo. Por outro lado, o desprazer inclui palavras que combinam alto efeito negativo e baixo efeito positivo. Quanto ao eixo forte empenho, os termos têm cargas moderadamente positivas em ambos os fatores de humor, enquanto que aqueles que representam o baixo empenho carregam negativamente em cada dimensão.

A fim de realizar a adequação da escala PANAS para a avaliação de sentimentos associados às características do ambiente construído, fez-se necessário o ajuste dos sentimentos nela contidos. Para tanto os 48 sentimentos nela presentes foram traduzidos de sua versão original do Inglês (WATSON; TELLEGEN, 1985) para a língua portuguesa, com auxílio do dicionário Oxford (2009) de Inglês/Português. Na sequência, as traduções dos sentimentos foram comparadas à versão portuguesa do questionário, desenvolvida por Galinha e Ribeiro (2005), a fim de serem verificadas eventuais diferenças entre elas, assim resultando na escala adaptada mostrada na figura 3.

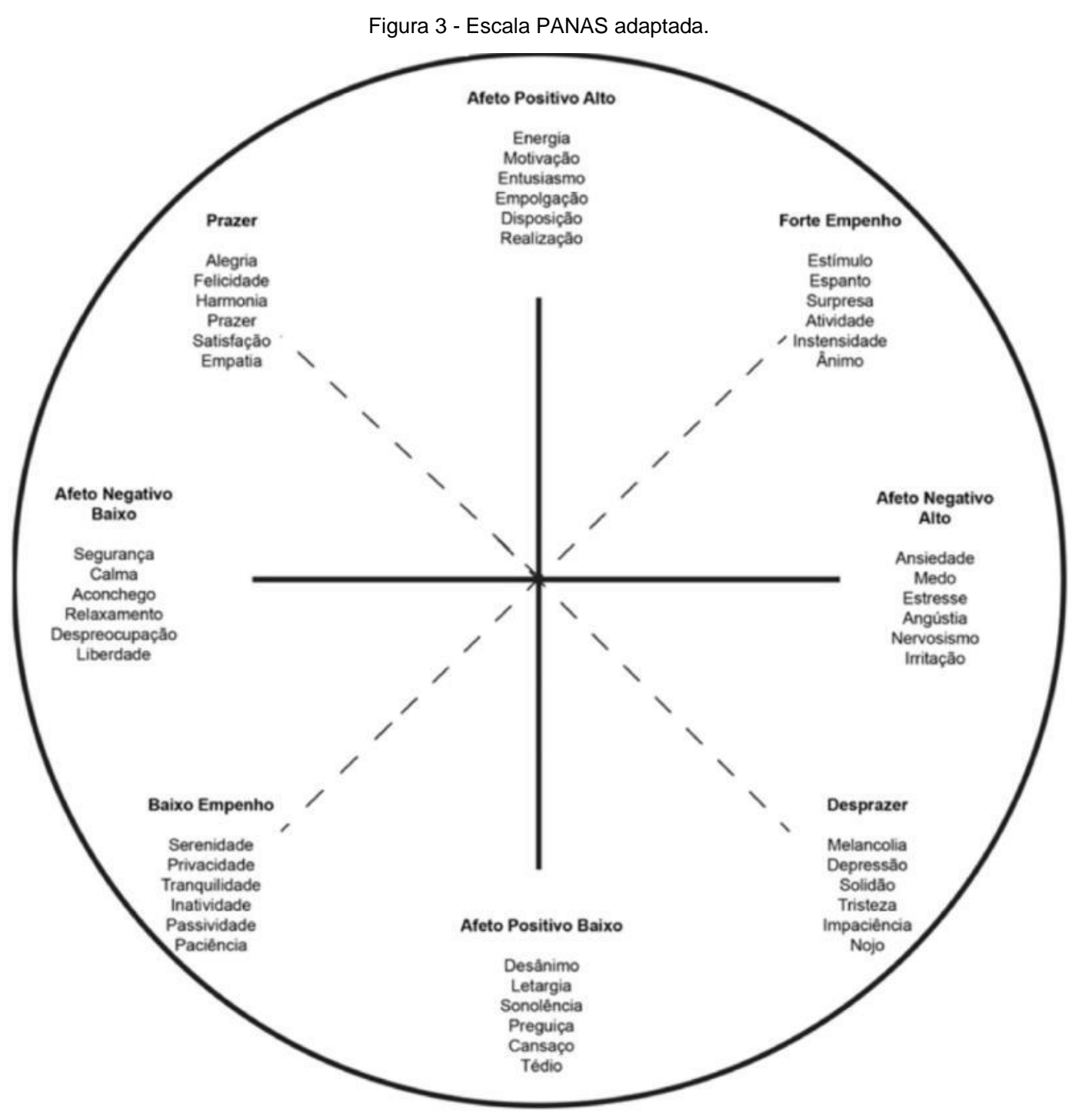

Fonte: Autores (2020)

A escolha dos ambientes avaliados ocorreu com base em critérios relacionados: a área, a altura do pé direito, ao volume, as cores (paredes e piso), ao tipo de mobiliário e a iluminação natural (área de janelas) e artificial (número de luminárias). Os ambientes disponíveis para a seleção estavam localizados no campus de uma Universidade Pública. Pretendeu-se avaliar ambientes que contemplassem características diversas, descritas na Tabela 1, para que cada ambiente fosse único em sua avaliação. A intenção era dispor de ambientes bem caracterizados e com bastante contraste em relação a suas características de modo a impactar efetivamente nos sentimentos. 
Penteado, A. C. B; larozinski Neto, A.

Tabela 1: Características dos cinco ambientes avaliados.

\begin{tabular}{|c|c|c|c|c|c|}
\hline & Ambiente 1 & Ambiente 2 & Ambiente 3 & Ambiente 4 & Ambiente 5 \\
\hline Dimensões & $9,90 \mathrm{~m} \times 7,20 \mathrm{~m}$ & $7,50 \mathrm{~m} \times 8,00 \mathrm{~m} \mathrm{e} 6,00 \mathrm{~m} \times 2,70 \mathrm{~m}$ & $19,60 \mathrm{~m} \times 8,20 \mathrm{~m}$ & $4,00 \mathrm{~m} \times 3,70 \mathrm{~m}$ & $5,70 \mathrm{~m} \times 6,40 \mathrm{~m}$ \\
\hline Área total & $71 \mathrm{~m}^{2}$ & $76 \mathrm{~m}^{2}$ & $160 \mathrm{~m}^{2}$ & $15 \mathrm{~m}^{2}$ & $36 \mathrm{~m}^{2}$. \\
\hline $\mathrm{N}^{0}$ de janelas & 4 & 10 & 19 & 1 & 6 \\
\hline Área das janelas & $8,2 m^{2}$ & $8 m^{2}$ & $10 \mathrm{~m}^{2}$ & $3,75 \mathrm{~m}^{2}$ & $19 m^{2}$ \\
\hline $\mathrm{N}^{0}$ de portas & 1 & 3 & 2 & 1 & 1 \\
\hline Tamanho das Portas & $2,00 \mathrm{~m} \mathrm{x} 2,10 \mathrm{~m}$ & $1,00 \mathrm{~m} \times 2,10 \mathrm{~m}$ & $1,60 \mathrm{~m} \times 2,10 \mathrm{~m}$ & $0,80 \mathrm{~m} \times 2,10 \mathrm{~m}$ & $1,00 \mathrm{~m} \times 2,10 \mathrm{~m}$ \\
\hline Pé-direito & $3,40 \mathrm{~m}$ & $3,40 \mathrm{~m}$ & $3,40 \mathrm{~m}$ & $4,5 \mathrm{~m}$ & $3,40 \mathrm{~m}$ \\
\hline $\mathrm{N}^{\circ}$ de iluminárias & 12 & 10 & 24 & 4 & 8 \\
\hline Cor do ambiente & Branca & Marrom claro & Branca & Branca & Branca \\
\hline Tipo de piso & Vinílico & Granilite & Vinílico & Granilite & Vinílico \\
\hline \multirow{2}{*}{ Móveis } & \multirow{2}{*}{45 carteiras e cortinas azuis } & \multirow{2}{*}{ Armários, mesas e cadeiras } & \multirow{2}{*}{ Sem móveis } & Duas mesas, duas & Dois sofás, seis poltronas, \\
\hline & & & & cadeiras e armário & uma mesa de centro \\
\hline
\end{tabular}

Fonte: Autores (2020).

O objetivo foi verificar quais eram os sentimentos sensíveis às mudanças das características de cada ambiente e assim, os entrevistados avaliaram os cinco ambientes definidos a seguir.

- O primeiro ambiente escolhido foi a sala de aula (Figura 4), considerado como neutro devido à familiaridade dos respondentes; além disso, as salas de aula seguem um padrão dentro da universidade, de modo que cada turma pode avaliar a sala de aula em que se encontrava, sem necessidade de deslocamento.

- O segundo ambiente foi o Laboratório de Saneamento, localizado no subsolo do Bloco de Engenharia Civil da Universidade (Figura 5); ele é caracterizado por utilizar cores mais escuras que os demais, e por uma incidência mais baixa de iluminação natural e artificial.

- O terceiro ambiente foi uma sala ampla, presente no Bloco de Engenharia Civil (Figura 6), que se caracteriza por ser ampla, ter boa iluminação e utilizar cores claras.

- O quarto ambiente (Figura 7) foi o menor de todos, correspondendo a uma pequena sala, caracterizada por sua área reduzida e por ter pé direito alto.

- O quinto ambiente foi a sala de espera do bloco do Programa de Pós-Graduação em Engenharia Civil (Figura 8), à qual foram acrescentados elementos de decoração (almofadas nas poltronas e um vaso com flor na mesa de centro), pois a intenção era criar um ambiente mais agradável do que os demais.

Figura 4: Sala de Aula.

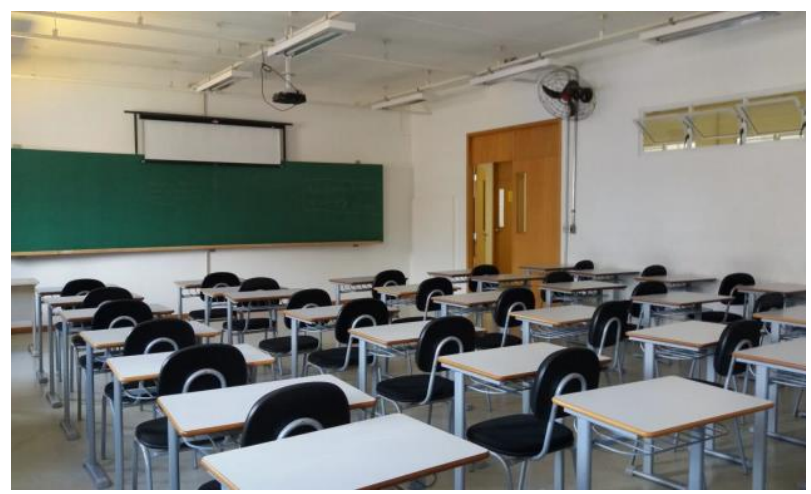

Figura 5: Subsolo.

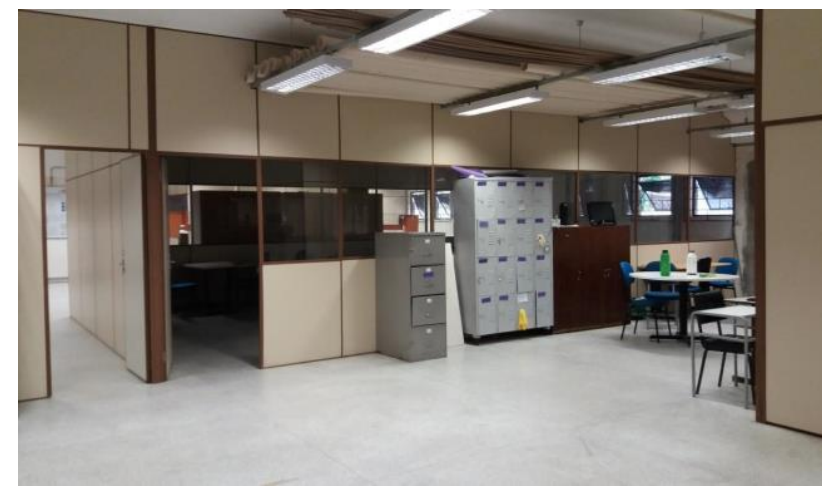

Fonte: Autores (2020). 
Figura 6: Sala Ampla.

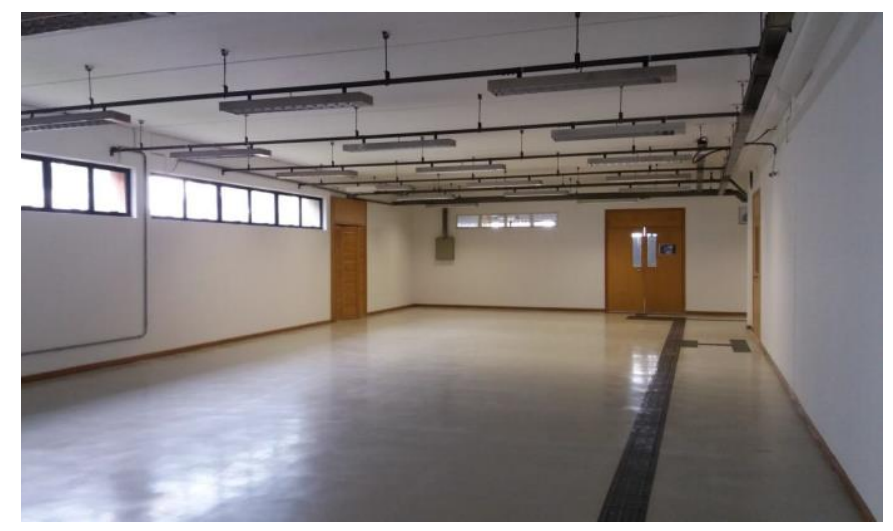

Fonte: Autores (2020).

Figura 7: Sala Pequena.

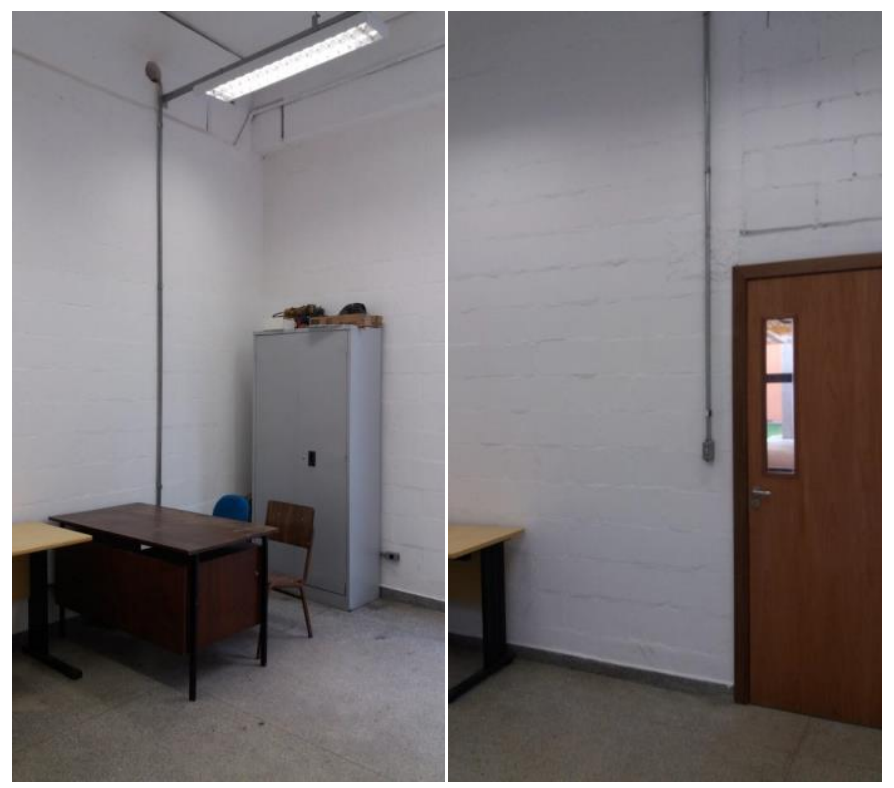

Fonte: Autores (2020).

Figura 8: Sala de Recepção.

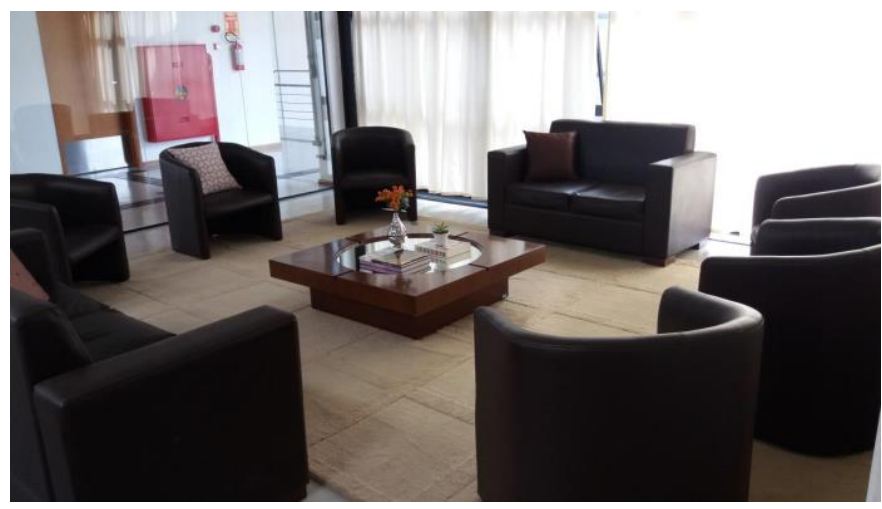

Fonte: Autores (2020).

A segunda etapa do experimento compreendeu a avaliação dos cinco ambientes internos selecionados. Foram aplicados 143 questionários em sala de aula de Arquitetura e Urbanismo e de Engenharia Civil, delimitando uma amostra definida por conveniência. 
Após permanecerem no ambiente em estudo por 2 a 5 minutos (aproximadamente), os entrevistados eram convidados a responder ao questionário sobre sua percepção, contemplando 48 sentimentos relacionados ao ambiente em que se encontravam. Eles foram orientados a indicar a intensidade que melhor expressava tais sentimentos.

Ao final da avaliação do primeiro ambiente (sala de aula), os entrevistados eram conduzidos ao segundo ambiente, e a partir dele, terminado o preenchimento, cada entrevistado era informado sobre a próxima sala a ser avaliada, podendo se encaminhar de maneira independente até ela, onde encontravam outro pesquisador capaz de orientar o preenchimento do instrumento e informar o próximo ambiente do experimento.

No que diz respeito ao questionário, o mesmo consistiu em duas partes, em que a primeira tem a função de identificar o perfil do entrevistado, a segunda objetiva a distinção (dentro dos 48 sentimentos selecionados) dos sentimentos que são evocados de maneira mais significativa pelos indivíduos dentro dos ambientes. Ele foi elaborado intercalando de maneira aleatória os eixos referentes ao afeto positivo alto e baixo, ao afeto negativo alto e baixo, prazer, desprazer, forte empenho e baixo empenho. Para as respostas dos entrevistados foi utilizada uma escala Likert de sete pontos, variando de -3 (que correspondia a "discordo totalmente") a +3 ("concordo totalmente").

As ferramentas de apoio utilizadas na transformação/sistematização dos dados e nas análises estatísticas foram o aplicativo Microsoft Excel 2010 e o software Statistical Package for the Social Sciences (SPSS), versão 22.

\section{RESULTADOS}

A presente seção apresenta a análise dos dados coletados, a qual foi fundamentada em estatística descritiva, e se dividiu em duas partes: o perfil da amostra e a análise da percepção dos respondentes em relação aos cinco ambientes

\section{Perfil dos Participantes}

Com relação à identificação do perfil dos participantes, as respostas relacionadas à idade mostraram que grande parte dos respondentes têm menos de 25 anos, o que se caracteriza pelo fato de serem estudantes.

Do total de 143 respondentes, $77 \%$ têm menos de 25 anos, $22 \%$ encontram-se na faixa dos 25 aos 40 anos e apenas $1 \%$ têm entre 41 e 55 anos. Em referência ao gênero dos respondentes, $51 \%$ são pertencentes ao gênero masculino e $49 \%$ são do gênero feminino.

Quanto ao nível de escolaridade dos respondentes, os resultados mostram que $85 \%$ estão na Graduação e $15 \%$ na Pós-graduação. A respeito da orientação profissional, $75 \%$ são estudantes do curso de Engenharia Civil e $25 \%$ pertencem ao curso de Arquitetura e Urbanismo.

\section{A percepção dos usuários por ambiente}

A segunda análise consistiu na avaliação de cinco ambientes com características e usos distintos pelos respondentes, que mensuraram a intensidade que melhor expressava os 48 sentimentos propostos na escala, em relação ao ambiente construído em que se encontravam.

Para analisar cada ambiente, foram elaborados gráficos do tipo radar, elaborados a partir das medianas das respostas dos participantes. Além disso, o modelo de gráfico assemelha-se ao modelo proposto pela escala PANAS, a fim de que a visualização dos gráficos e do modelo fiquem próximas.

No que se diz respeito ao agrupamento dos sentimentos de PANAS, os sentimentos de bem-estar estão na parte superior do gráfico, segundo os eixos afeto positivo alto, prazer, afeto negativo baixo e forte empenho. $\mathrm{Na}$ parte inferior do gráfico estão os sentimentos associados ao mal-estar, correspondendo aos eixos afeto positivo baixo, baixo empenho, desprazer e afeto negativo alto. 


\section{a) Avaliação do Ambiente 1 - Sala de Aula}

A sala de aula, que foi o primeiro ambiente a ser avaliado. Ela segue ao padrão utilizados dentro da universidade, sendo assim cada turma pôde avaliar a própria sala, sem necessidade de deslocar-se. Após a observação do ambiente em que se encontravam, os respondentes preencheram o questionário contendo os 48 sentimentos da escala, especificando a intensidade dos mesmos através da Escala Likert (sete pontos).

Ao se analisar as respostas dos 143 participantes em relação ao primeiro ambiente foi possível perceber-se que a distribuição das medianas foi constante com relação à maior parte dos sentimentos (Gráfico 1), sendo seu valor igual a 4, o que apresenta homogeneidade nas respostas. As maiores medianas se relacionaram aos sentimentos ligados ao afeto positivo baixo, sendo que "tédio", "cansaço" e "preguiça" atingiram mediana 5 e "sonolência" atingiu a maior mediana (equivalente a 6). O sentimento de "segurança", também demonstrou ser sentido com grande intensidade (tendo obtido mediana 5).

As características da sala de aula tenderam a despertar os sentimentos presentes no eixo do afeto positivo baixo, onde estão as maiores medianas, e em um sentimento do afeto negativo baixo. $O$ fato de os participantes do experimento estarem habituados com 0 ambiente e com o cotidiano das aulas, provavelmente, influenciou diretamente na expressão de seus sentimentos. Neste caso, a familiaridade e o uso do ambiente foram determinantes nos sentimentos dos indivíduos.

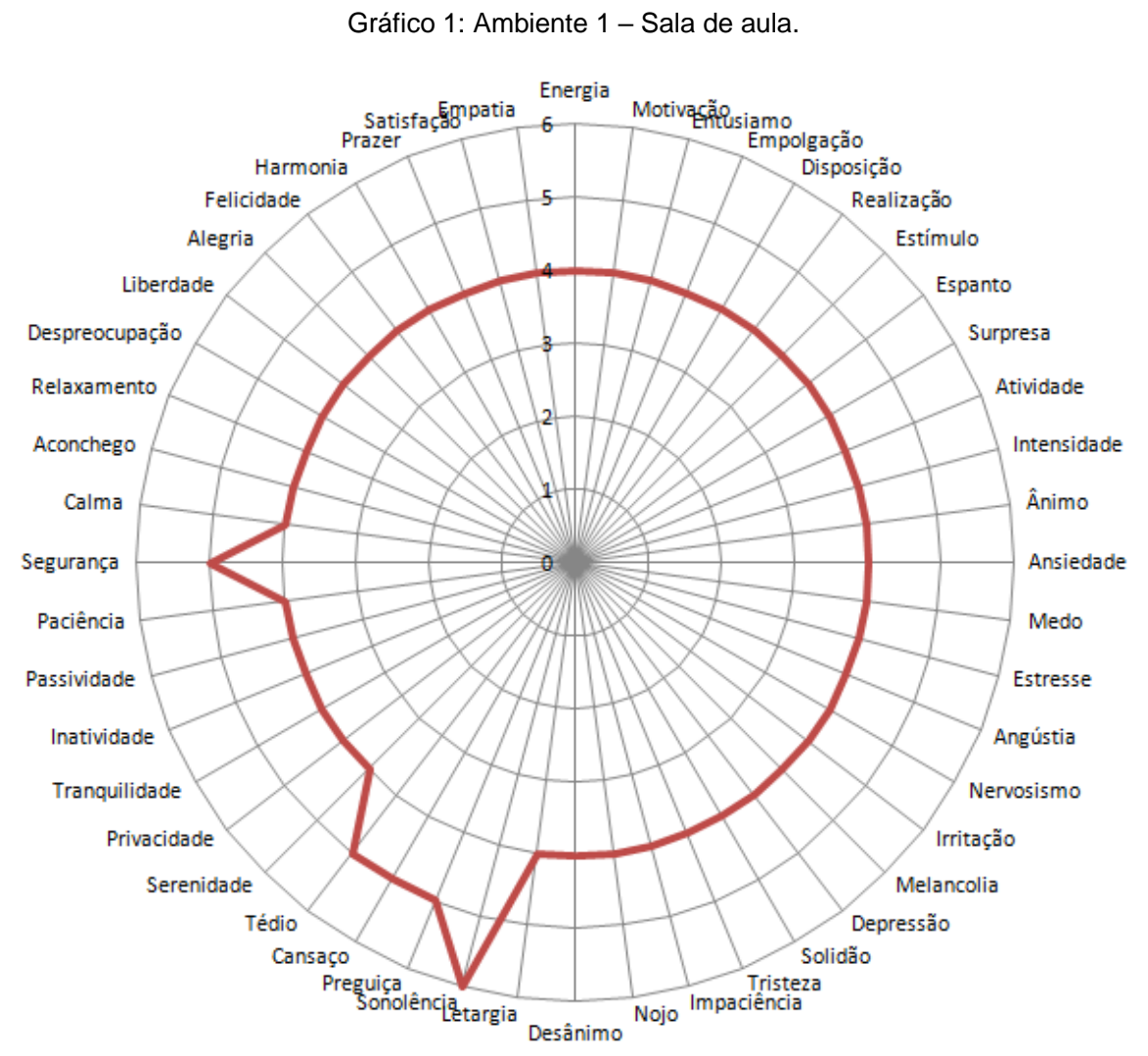

Fonte: Autores (2020).

\section{b) Avaliação do Ambiente 2 - Subsolo}

O laboratório de saneamento presente no subsolo do bloco de Engenharia Civil da Universidade foi o segundo ambiente avaliado. O mesmo procedimento foi realizado pelos respondentes no primeiro ambiente, avaliando as suas características e repetindo o preenchimento do questionário.

É possível observar na parte inferior do gráfico (Gráfico 2), que sentimentos relacionados aos eixos de baixo empenho, afeto positivo baixo, desprazer e afeto negativo alto, se distribuíram de forma homogênea, com mediana equivalente a 4 , com destaque para sentimento de maior mediana 5, "desânimo" (afeto positivo 
baixo). Isso demonstra que houve uma tendência de os respondentes sentir com maior intensidade sentimentos relacionados ao mal-estar nesse ambiente.

$\mathrm{Na}$ parte superior do gráfico, onde se encontram os sentimentos relacionados ao bem-estar, presentes nos eixos do afeto negativo baixo, prazer, afeto positivo alto e forte empenho, os mesmos tiveram as menores medianas, ou seja, os entrevistados tenderam a senti-los com menor intensidade.

O sentimento "aconchego" (afeto negativo baixo) obteve a menor mediana, equivalente a 2; três sentimentos do eixo prazer obtiveram mediana 3, sendo eles: "prazer", "satisfação" e "alegria". Houve uma tendência de os entrevistados sentirem em grau superior os sentimentos de mal-estar e com maior intensidade o sentimento "desânimo", presente no afeto positivo baixo.

O eixo referente ao afeto positivo alto é o que tem a menor tendência a ser evocado e o sentimento menos evocado foi "aconchego", presente no eixo afeto negativo baixo. Visto que se trata de um ambiente onde são realizados experimentos relacionados ao saneamento, esperava-se que o ambiente pudesse despertar tais sentimentos de mal-estar no participante.

Este ambiente não é tão familiar para os respondentes como a sala de aula. Os respondentes o utilizam esporadicamente. Ele é caracterizado pela pouca iluminação natural e artificial, pelas cores mais escuras e pelos móveis serem distribuídos de maneira quase aleatória. Estes fatores, certamente, contribuem para a prevalência dos sentimentos com viés negativo.

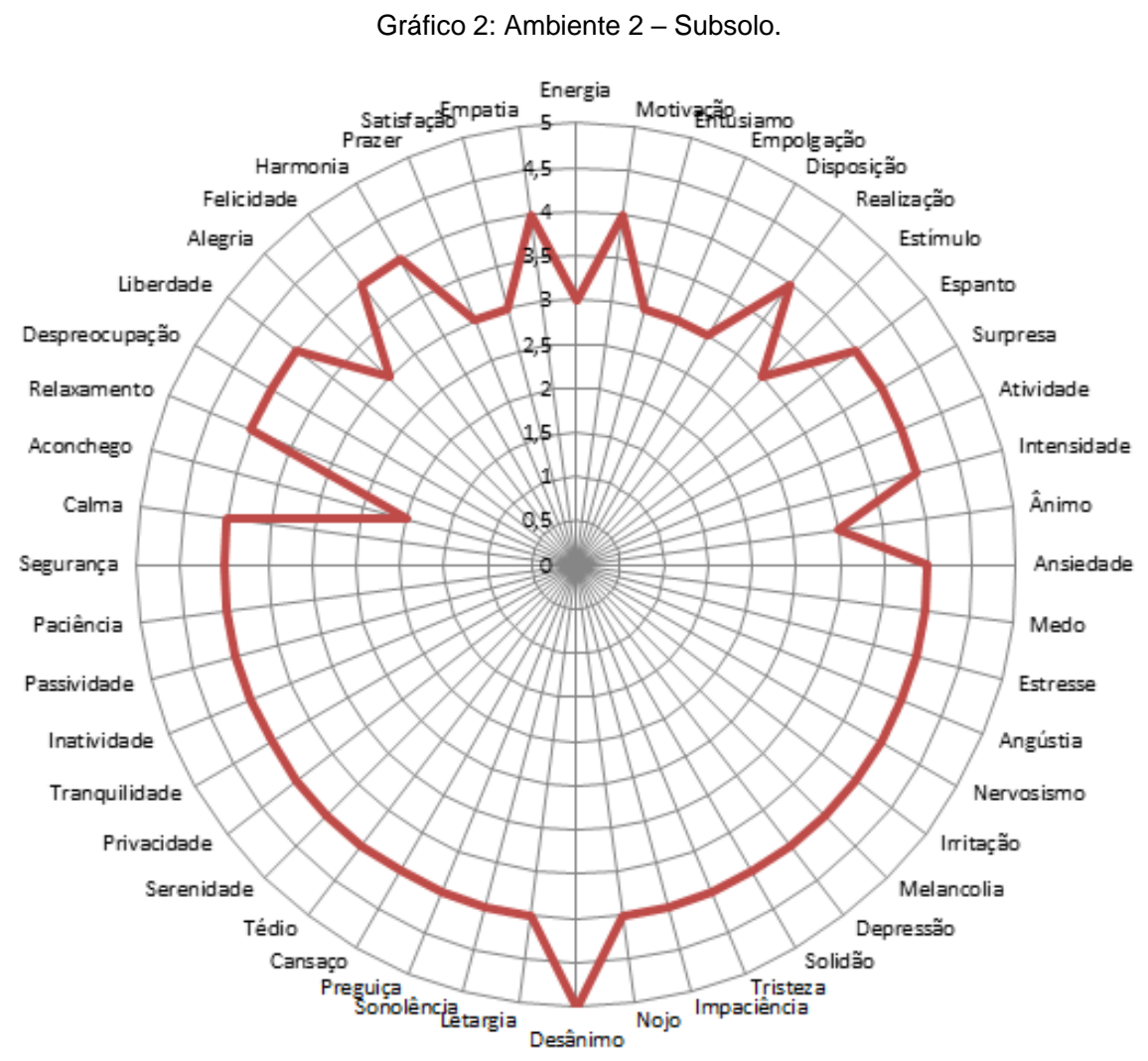

Fonte: Autores (2020).

\section{c) Avaliação do Ambiente 3 - Sala Ampla}

O ambiente 3 - sala ampla, era um local totalmente desconhecido dos respondentes. Ele tinha uma boa iluminação natural e artificial, não possuía nenhum elemento de mobiliário e as paredes eram pintadas de branco.

No gráfico 3 observa-se uma homogeneidade entre os sentimentos despertados nos respondentes, sendo eles dos eixos de forte empenho, afeto negativo alto e afeto positivo baixo, com medianas equivalentes a 4 . 
Além disso, no eixo do desprazer, apenas o sentimento "nojo" mostrou mediana igual a 3, ou seja, o ambiente tende a não evocar esse sentimento nos respondentes.

Quanto ao eixo baixo empenho, três sentimentos também obtiveram mediana igual a 4 , sendo eles "inatividade", "passividade" e "privacidade", porém houve um aumento significativo na mediana de "tranquilidade", equivalente a 6 , sendo esse o sentimento com maior tendência a ser evocado. Houve uma acentuada elevação dos sentimentos do eixo afeto negativo baixo, especialmente "calma", de mediana igual a 6 e "relaxamento" e "liberdade".

Também pode-se perceber que tal ambiente tem tendência a transmitir sensações de serenidade, tranquilidade, calma, segurança e relaxamento, o que pode ser explicado pelas características que ele apresenta. $\mathrm{O}$ fato de ser um ambiente com muita amplitude, cores claras e muitas janelas, promove a incidência de bastante iluminação natural, o que torna o local agradável e proporciona maior conforto aos indivíduos que o utilizam.

\section{Gráfico 3: Ambiente 3 - Sala Ampla.}

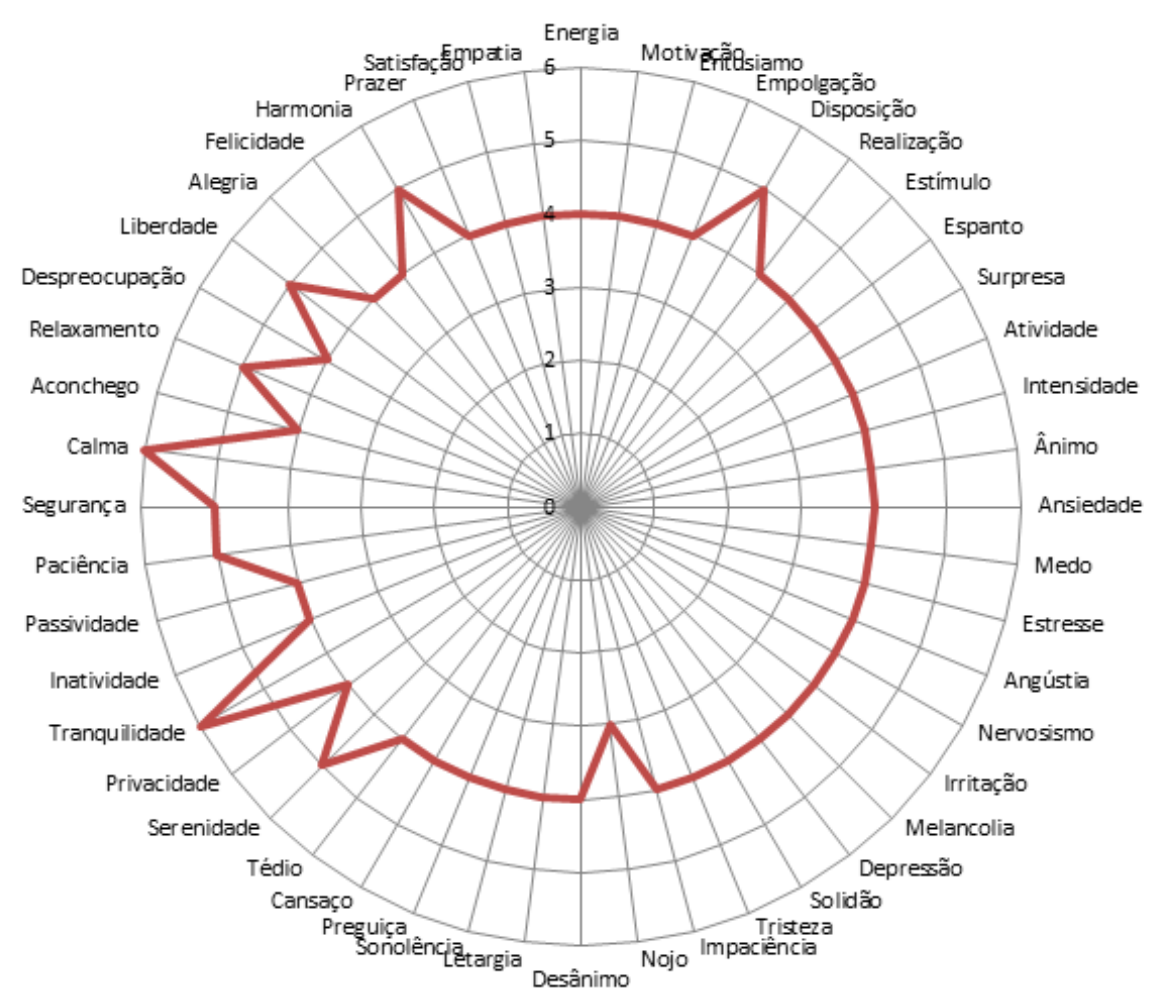

Fonte: Autores (2020).

\section{d) Avaliação do Ambiente 4 - Sala Pequena}

O ambiente 4 - sala pequena, também era totalmente desconhecido pelos respondentes. Ele é caracterizado por ter uma área pequena porém um pé direito muito alto. Durante a pesquisa ele dispunha de poucos elementos de mobiliário, suas paredes eram pintadas de branco, e a iluminação natural e artificial foram consideradas adequadas.

Os resultados relacionados ao ambiente 4 se mostraram bastante homogêneos (Gráfico 4), visto que os sentimentos relacionados aos oitos eixos de PANAS obtiveram as medianas das respostas mais próximas do valor 4. Dois sentimentos obtiveram as medianas mais altas, equivalentes a 5 , sendo eles: "tranquilidade", presente no eixo baixo empenho e "tédio", presente no afeto positivo baixo.

O ambiente avaliado demonstrou tendência a despertar sentimentos de tédio e tranquilidade nos participantes, o que pode ser associado às suas características relativas ao pé direito alto, poucos elementos de mobília e das cores claras. 


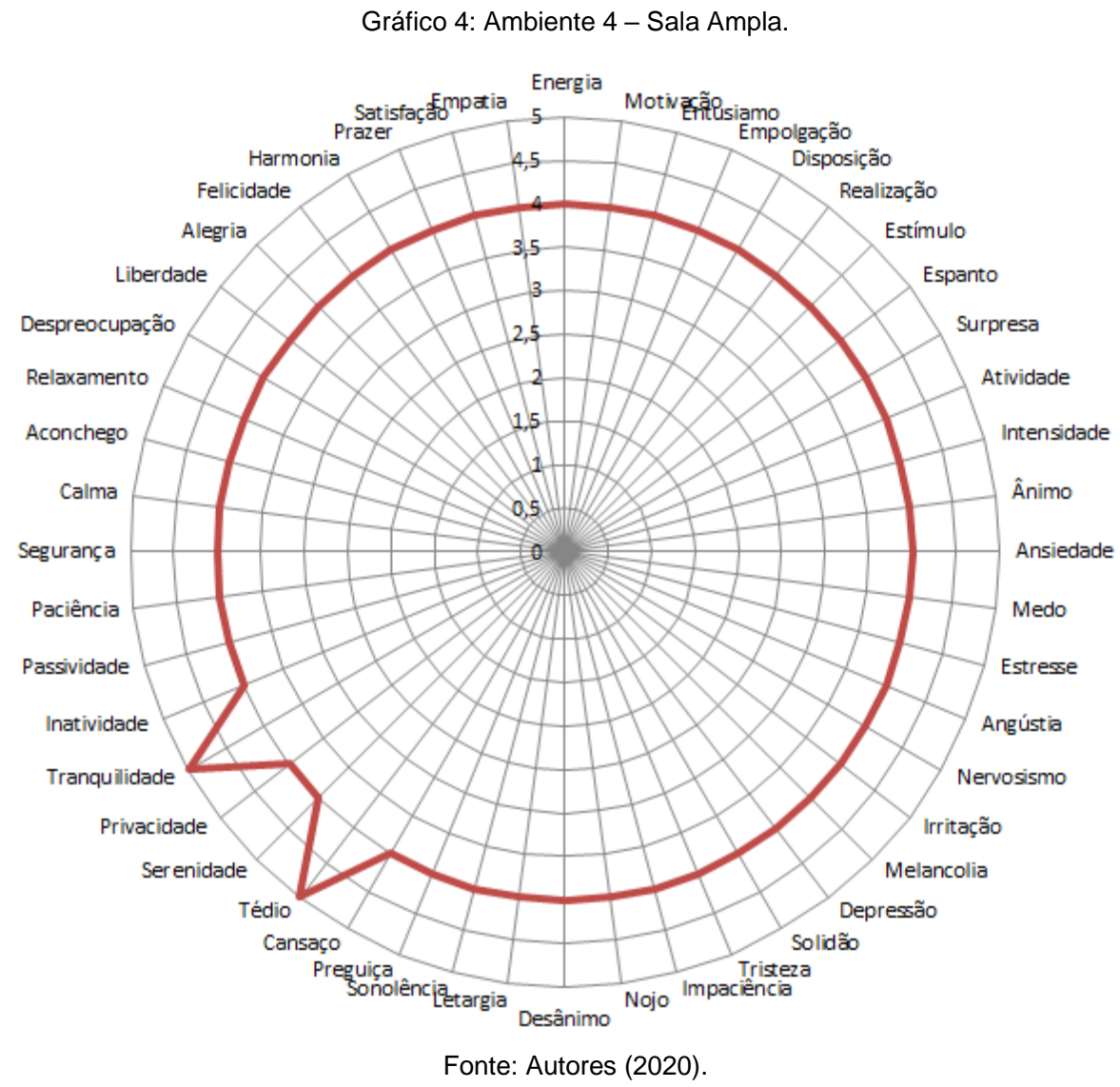

\section{e) Avaliação do Ambiente 5 - Sala de Espera}

O quinto ambiente avaliado foi a sala de espera do bloco de engenharia da Universidade. Este era um ambiente mais familiar dos respondentes. Ele é utilizado ocasionalmente pelos respondentes nos intervalos de algumas aulas que são ministradas próximo ao local. Durante a aplicação do experimento pensou-se em criar um ambiente mais agradável e semelhante a um ambiente residencial, por meio da inclusão de elementos de decoração.

A partir das respostas dos participantes, observou-se que a parte superior do gráfico 5 , onde estão os sentimentos de bem-estar, possui as medianas mais altas. Já a parte inferior do gráfico, referentes aos sentimentos de mal-estar, apresenta as medianas mais baixas, mostrando assim a tendência dos participantes a senti-los com menor intensidade.

Com relação aos sentimentos que atingiram as medianas máximas, equivalentes a 6 , tais foram: "tranquilidade", presente no eixo baixo empenho; "segurança", "calma", "aconchego" e "relaxamento", presentes no eixo afeto negativo baixo; e "satisfação", presente no eixo prazer.

Nos eixos afeto positivo alto e eixo prazer, a maioria dos sentimentos também obtiveram mediana 5 . Já o eixo forte empenho "estímulo" e "ânimo" obtiveram mediana 5.

O eixo afeto negativo alto mostrou medianas menores, com valor igual a 3, em "medo", "estresse", "angústia" e "irritação". De maneira semelhante, os resultados do eixo desprazer mostram que três sentimentos obtiveram mediana 3, sendo eles "depressão", "solidão" e "tristeza"; além disso, "nojo" foi sentido com menor intensidade dentre todos os 48 sentimentos, com mediana igual a 2 .

O eixo que tendeu a ter maior frequência de sentimentos evocados foi afeto negativo baixo, onde quatro sentimentos "segurança", "calma", "aconchego" e "relaxamento" tiveram mediana igual a 6.

Pode-se dizer que, por meio dos resultados sobre a percepção dos respondentes, um ambiente semelhante ao doméstico é capaz de trazer mais sensações positivas aos seus usuários em relação aos outros avaliados, pois houve maior distinção entre medianas no gráfico.

De certa forma, a complexidade deste ambiente, representada pela diversidade dos elementos de mobiliário e decoração, refletiu-se na complexidade dos sentimentos expressados pelos respondentes. 


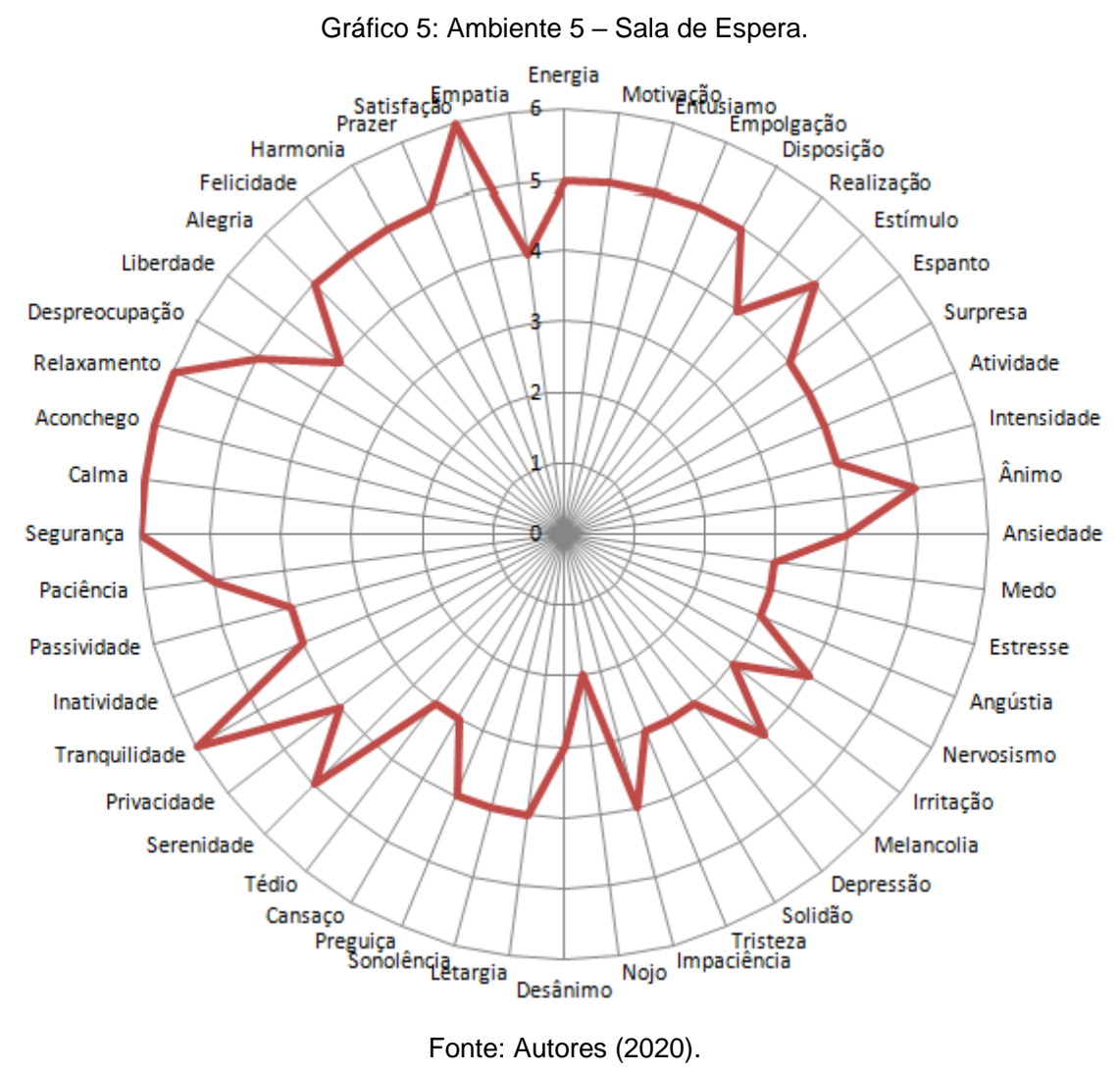

\section{Análise conjunta da percepção dos ambientes}

Ao se realizar uma análise conjunta dos cinco ambientes (Gráfico 6), pode-se perceber que se mostram mais neutros os ambientes 1 (sala de aula) e 4 (sala pequena) dentro dos cinco avaliados, pois a distribuição das medianas de ambos se manteve constante na maior parte dos sentimentos, com valor igual a 4. Com relação ao primeiro ambiente, a sala de aula, os sentimentos ligados ao afeto positivo baixo tiveram as maiores medianas (equivalentes a 5), sendo eles "tédio", "cansaço" e "preguiça". Além deles, "segurança" presente no afeto negativo baixo também é sentida com maior intensidade, com mediana 5.

Dentro do ambiente 4, apenas dois sentimentos se sobressaíram, sendo eles "tranquilidade", presente no eixo baixo empenho e "tédio", presente no afeto positivo baixo, obtendo as medianas mais altas, equivalentes a 5. Já no terceiro ambiente (sala ampla) houve maior ocorrência de sentimentos de baixo empenho e afeto negativo baixo, ou seja, o ambiente tendeu a transmitir sensações de serenidade, tranquilidade, calma, segurança e relaxamento. É um reflexo de suas características, visto que é um ambiente muito amplo, de cores claras e boa ventilação.

No que diz respeito ao ambiente 2, houve uma tendência de os respondentes sentirem mais intensamente sentimentos relacionados ao mal-estar, especialmente "desânimo", com a maior mediana, equivalente a 5 (afeto positivo baixo). Já os sentimentos de bem-estar (eixos do afeto negativo baixo, prazer, afeto positivo alto e forte empenho) tiveram as menores medianas, ou seja, os entrevistados tenderam a senti-los com menor intensidade.

O ambiente 5 (sala de recepção), em comparação ao ambiente 2 (laboratório no sub-solo), mostra o contrário, pois os sentimentos de bem-estar, especialmente "tranquilidade", presente no eixo baixo empenho, "segurança", "calma", "aconchego" e "relaxamento", no eixo afeto negativo baixo, e "satisfação", presente no eixo prazer, demonstraram medianas mais altas. Na parte inferior do gráfico, os sentimentos de mal-estar, apresenta as medianas mais baixas: no eixo afeto negativo alto, "medo", "estresse", "angústia" e "irritação" (mediana igual a 3); no eixo desprazer, "depressão", "solidão" e "tristeza" (mediana igual a 3); e "nojo" com mediana igual a 2, mostrou assim a tendência dos participantes a senti-los com menor intensidade. 
Gráfico 6: Análise conjunta dos ambientes.

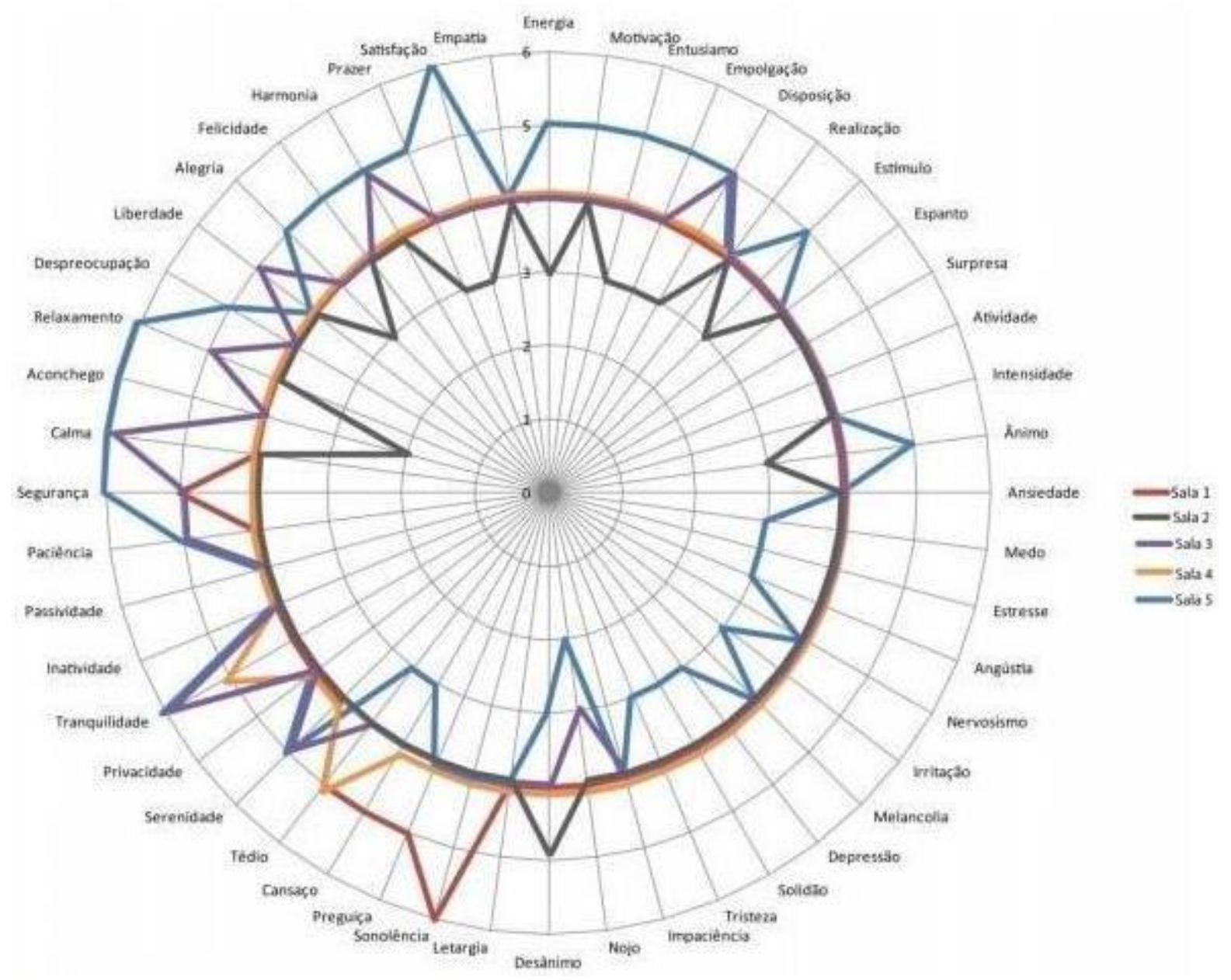

Fonte: Autores (2020).

\section{CONCLUSÃO}

O estudo apresentado neste artigo se propôs a avaliar a variação dos sentimentos de bem-estar em indivíduos em função da variação das características e usos ambientes distintos. Para esse propósito, foram analisados sentimentos mais sensíveis às variações das características do ambiente construído e que foram percebidos com maior intensidade pelos indivíduos. Tais resultados atestaram que ambientes com diferentes características e usos tendem a despertar diferentes percepções em seus usuários. Os resultados apresentados demonstraram a variação dos sentimentos nos cinco ambientes avaliados vinculados ao modelo de PANAS.

A análise dos dados mostra que no processo de percepção do ambiente construído o indivíduo inserido no espaço é capaz de "sentir" o ambiente em função da variação de suas características. Os resultados confirmaram que ambientes de diferentes características e usos tendem a despertar diferentes percepções em seus usuários. Os resultados apresentados na forma de gráfico do tipo radar, vinculados ao modelo PANAS, facilita a visualização sobre quais tipos de sentimentos, relacionados ao bem-estar ou mal-estar, se associam a cada ambiente em particular. Eles podem ser entendidos como "mapas dos sentimentos" dos indivíduos. Estes mapas mostraram o reflexo exteriorizado dos sentimentos moldados a partir das características do ambiente que vivência o indivíduo.

A familiaridade com ambiente trouxe uma influência maior do uso do ambiente nos sentimentos expressos pelos indivíduos, enquanto, que a novidade em relação ao ambiente, resultou numa influência mais direta das características do ambiente analisado nos sentimentos percebidos pelos indivíduos. 
Sendo uma pesquisa exploratória, ela representa um primeiro passo na direção ao entendimento acerca da percepção do indivíduo em relação ao ambiente construído, a fim de que projetos sejam capazes de contemplar conceitos ligados à percepção que os indivíduos têm sobre o espaço, visto que a avaliação e mensuração do bem-estar auxiliam na melhoria da qualidade de vida e do bem-estar dos indivíduos, refletidos em espaços.

Um segundo passo da pesquisa seria a repetição do experimento com um controle aprimorado das condições ambientais (temperatura, umidade, luminosidade, nível de ruído, etc.), com o uso de uma versão reduzida da escala portuguesa de afeto positivo e negativo- PANAS (GALINHA et al., 2014) e a utilização de ambientes com diferenças nas características e usos (ambientes comerciais, domésticos e de trabalho). Para que, dessa forma, os resultados sejam mais sensíveis as diferenças nas características dos ambientes, nos seus usos, contemplando e explorando outros grupos de usuários em termos de segmentação e de diferenciação.

Finalmente, pode-se dizer que, em síntese, os sentimentos pelos ambientes construídos evocados nos usuários são uma expressão da complexidade destes próprios ambientes.

\section{REFERÊNCIAS}

ALBUQUERQUE, Anelise Salazar; TROCCÓLI, Bartholomeu Tôrres. Desenvolvimento de uma escala de bem-estar subjetivo. In: Psicologia: Teoria e pesquisa. Vol. 20 n. 2 pp. 153-164. Mai-Ago 2004.

BUZ J, PEREZ-ARECHAEDERRA D; FERNANDEZ-PULIDO R; URCHAGA D. Factorial structure and measurement invariance of the PANAS in Spanish older adults. The Spanish Journal of Psychology 18(e3):1-11, 2015.

CRAWFORD, J. R., HENRY, J. D. The Positive and Negative Affect Schedule (PANAS): Construct validity, measurement properties and normative data in a large non-clinical sample. British Journal of Clinical Psychology, 43, 245-265, 2004.

FORSBERG, A; MALMBERG, F. Tools for environmental assessment of the built environment. Building and Environment. Vol. 39, Pp $223-228,2004$.

GALÁN-DÍAZ, Carlos Roberto. Responses to representations of the built environment: the influence of emotion, attention and perspective-taking. Tese (Doutorado em Psicologia) The Robert Gordon University, 2011.

GALINHA, lolanda Costa; RIBEIRO, José Luis Pais. Contribuição para o estudo da versão portuguesa da Positive and Negative Affect Schedule (PANAS) I - Abordagem teórica ao conceito de afecto. Análise Psicológica (2005), 2 (XXIII): 209-216 - Portugal, 2005.

GALINHA, Iolanda Costa; PEREIRA, Cicero Roberto; ESTEVES, Francisco. Versão reduzida da escala portuguesa de afeto positivo e negativo - PANAS-VRP: Análise fatorial confirmatória e invariância temporal. Psicologia, Lisboa, v. 28, n. 1, p. 50-62, jun. 2014 Disponível em <http://www.scielo.mec.pt/scielo.php?script=sci arttext\&pid=S087420492014000100005\&lng=pt\&nrm=iso >. acessos em 20 nov. 2020.

KNEZ, I., KERS, C. Effects of indoor lighting, gender and age on mood and cognitive performance. Environment and Behavior, vol. 32 n. 6, 2000.

ORNSTEIN, S., Desempenho do Ambiente Construído, Interdisciplinaridade e Arquitetura. São Paulo: FAUUSP, 1995.

OXFORD. Oxford advanced learner's dictionary. Oxford: Oxford University Press, 2009.

REIS, Antônio Tarcísio da Luz; LAY, Maria Cristina Dias. Avaliação da qualidade de projetos - uma abordagem perceptiva e cognitiva. In: Ambiente Construído, Porto Alegre, v.6, n.3, p. 21-34. jul./set. 2006.

SAYEGH A., ANDREANI S., KAPELONIS C., POLOZENKO N., STANOJEVIC S. Experiencing the built environment: strategies to measure objective and subjective qualities of places. Open Geospat Data Softw Stand, v.1, n.11, 2016.

SOBRAL, E.R.A.; PAIVA, M.M.B.; PORTO, N.R.S.; VILLAROUCO, V. Discussão acerca da percepção ambiental, suas ferramentas e cognição. Estudos em Design - Revista (online). Rio de Janeiro: v. 23, n. 3, p. 181-198, 2015.

WATSON, D; TELLEGEN, A.Toward a consensual structure of mood. Psychological Bulletin, v, 98, 219-235, 1985.

D; CLARK, L. A.; TELLEGEN, A. Development and validation of brief measures of positive and negative affect: The PANAS scale. Journal of Personality and So \& Psychology, v. 54, 1063-1070, 1988.

NOTA DO EDITOR $\left(^{*}\right)$ : O conteúdo do artigo e as imagens nele publicadas são de responsabilidade do(s) autor(es). 